\title{
Study on Seroprevalence and Risk Factors Contagious Bovine Pleuropneumonia in Southern Nation and Nationality People of Ethiopia Regional State in Amaro Special District
}

\author{
Tolesa Ebisa $^{1}$, Eyob Hirpa ${ }^{1^{*}}$ and Fasil Aklilu ${ }^{2}$ \\ ${ }^{1}$ School of Veterinary Medicine, Wollega University, P.O. Box: 395, Nekemte, Ethiopia \\ ${ }^{2}$ National Animal Health Diagnostic and Investigation Centre (NAHDIC), P.O. Box: 4, Sebeta, Ethiopia
}

\begin{tabular}{|c|c|}
\hline Abstract & Article Information \\
\hline $\begin{array}{l}\text { A cross-sectional study was conducted from November } 2014 \text { to April } 2015 \text { In Amaro special } \\
\text { District of SNNP region to determine the seroprevalence of Contagious Bovine Pleuro } \\
\text { Pneumonia (CBPP) and to assess the potential risk factors for the occurrence of the } \\
\text { disease. In this study a total of } 400 \text { sera were examined for the presence of specific } \\
\text { antibodies against Mycoplasma mycoides sub species mycoides small colony type by using } \\
\text { competitive Enzyme Linked Immunosorbent Asssay (c-ELISA). The overall seroprevalence } \\
\text { of CBPP in this study was } 127 / 400(31.8 \%) \text {. The seroprevalence of CBPP at peasant } \\
\text { association level was } 7 \%, 28 \%, 34 \% \text { and } 58 \% \text { in Jello, Kele, Golbe and Gamule PA's } \\
\text { respectively. There is Statistically significant Variation }(P<0.05) \text { between seroprevalence } \\
\text { result of the disease and peasant associations }\left(X^{2}=60.95, P=0.000\right) \text {, body condition }\left(X^{2}\right. \\
=10.645, P=0.005) \text { and herd size }\left(X^{2}=14.972, P=0.001\right) \text { were recorded. However other risk } \\
\text { factors such as age and sex were not significantly associated }(P>0.05) \text { with the sero status } \\
\text { of the animal. The major risk factors identified during this study were body condition and } \\
\text { associated uncontrolled cattle movement. In conclusion the present study indicated that the } \\
\text { overall prevalence of CBPP in SNNP region, Amaro special woreda was higher as compared } \\
\text { to other research findings. This warrants the need to institute for appropriate preventive and } \\
\text { control measures to stop further spread of this economically devastating disease. } \\
\text { Copyright@2015 STAR Journal, Wollega University. All Rights Reserved. }\end{array}$ & $\begin{array}{l}\text { Article History: } \\
\text { Received : 27-09-2015 } \\
\text { Revised : 05-12-2015 } \\
\text { Accepted : 19-12-2015 } \\
\text { Keywords: } \\
\text { Seroprevalence } \\
\text { CBPP } \\
\text { Risk factors } \\
\text { c-ELISA } \\
\text { *Corresponding Author: } \\
\text { Eyob Hirpa } \\
\text { E-mail: nafiyad@gmail.com } \\
\text { eyobresearch@gmail.com }\end{array}$ \\
\hline
\end{tabular}

\section{INTRODUCTION}

Contagious bovine pleuropneumonia (CBPP) is a contagious disease of cattle caused by Mycoplasma mycoides subsp. mycoides SC (bovine biotype) (Mmm $\mathrm{SC} ; \mathrm{SC}=$ small colonies). $\mathrm{CBPP}$ has been known to occur in Europe since the 16th century but it gained a worldwide distribution only during the second half of the 19th century because of increased international trade in live cattle. It was eradicated from many countries by the beginning of the 20th century through stamping-out policies. However the disease persists in many parts of Africa and in Southern Europe; the situation in Asia is unclear. There have been no reported outbreaks in Europe since 1999.In Ethiopia the disease mainly occurs in pastoral herd and in cattle derived from or in contact with them where close contact and stress favors rapid transmission (Schnee et al., 2011; Tardy, 2011).

Contagious bovine pleuro pneumonia is now reemerging as one of the most economically important diseases that impede livestock production in Ethiopia. It is a highly contagious disease with serious socioeconomic consequences at the farmer and national level hampering the export potential. Besides, the poorly understood pathogenesis, relatively ineffective vaccines or with adverse effects and poor diagnostic assays, further exacerbates the impact of CBPP. The main problem in eradication is the frequent occurrence of sub-acute or asymptomatic infections and the persistence of chronic carriers after the clinical phase. Serological analysis is the most important diagnostic tool for the control of CBPP, but it is significantly hampered by the relatively low sensitivity and specificity of the methods (Abdo et al., 2000; March et al., 2003; Vilei et al., 2000; Monnerat et al., 1999).

Contagious Bovine Pleuropneumonia (CBPP) is both an epidemic and endemic disease of cattle that affects production through mortality and reduction in productivity. It also retards genetic improvement and limits working ability of cattle (Tambi and Maina, 2004). Accordingly, cattle in CBPP-infected areas (epidemic and endemic) are divided into three classes namely, calves and yearlings below 3 years, adult males and reproductive females. The losses due to CBPP (epidemic and endemic) are measured as the number of deaths that occur per class of animal, the quantity of beef lost for each class of animal, the quantity of milk lost from reproductive females and the loss in draft power from oxen (Tambi et al., 2004).

In recent years its incidence in the highland areas has raised. In natural conditions, MmmSC affects only the 
Tolesa Ebisa et al.,

ruminants of the Bos genus, i.e. mainly bovine and zebu cattle. Wild animals do not play a role in the epidemiology of the disease. Anorexia, fever and respiratory signs, such as dyspnoea, polypnoea, cough and nasal discharges manifest CBPP. In the case of acute outbreaks in experimental conditions, the mortality rate may be as high as $50 \%$ in the absence of antibiotic treatment. This mortality rate may be much lower in the field; however, sometimes when an outbreak first occurs in an area, the mortality will be higher. Clinical signs are not always evident. Sub-acute or asymptomatic forms occur frequently as affected animals recover partially. In that case their lungs show typical encapsulated lesions called 'sequestra'. These animals may be responsible for unnoticed persistence of the infection in a herd or a region and play an important role in the epidemiology of the disease. Transmission of the disease occurs through direct contact of an infected animal with a naive one. There is no evidence of transmission through fomites as $M m m S C$ does not persist in the environment (Scacchia et al., 2011). The available major diagnostic assays are Serum Agglutination Slide Test (SAST), Complement Fixation Test (CFT) and Competitive Enzyme Linked Immunosorbent Assay (C-ELISA) which are used at herd level (Amanfu et al., 1998).

Control of the disease will involve vaccination, slaughter of sick and contaminated animals, control of cattle movement and implementation of strict quarantine measures to avoid introduction of the disease in clean areas. Active disease surveillance must be effective which needs a strong field services as well as proper laboratory facilities. Since CBPP has become a great concern in many African countries, it requires also cooperation network through which countries with this problem can share experiences, information and technology in order to stop transboundary transmission of the disease (Litamoi, 2000).

Given the large livestock population and distribution in the country and poor supply of veterinary services, infectious and parasitic diseases consequently cause death and debilitation to a significant number of animals. Animal health problems are generally exacerbated by drought, concentration of livestock at watering points and dry grazing grounds, combined with reduced resistance, intensifies the spread of communicable and parasitic diseases, which often cause higher losses than the forage or water shortages (The World Bank, 2001).

Although vaccination has been considered as a strategy for the control of CBPP in Ethiopia for the last 30 years, the disease still persists in several regions of the country, with its incidence increasing from year to year. This is, mainly due to lack of effective vaccine, irregular and low rate/coverage of vaccination, lack of livestock movement control, and absence of systematic disease surveillance and reliable data (Litamoi, 2000). The vaccines are exclusively monovalent live attenuated freeze-dried products derived from broth culture of T1SR (streptomycin resistant variant) or T1/44 seed strains of Mycoplasma mycoides subspecies mycoides small colony (SC) that gives protection for 6 months up to one year. The other vaccines are $\mathrm{V} 5, \mathrm{KH} 3 \mathrm{~J}$ that gives protection for 2 and 6 months (Bamhare, 2000).
Sci. Technol. Arts Res. J., Oct-Dec 2015, 4(4): 106-112

With the imminent eradication of rinderpest, Contagious Bovine Pleuropneumonia (CBPP) has become the most important cattle disease that hinders livestock development in Ethiopia. This is mainly due to the stoppage of the consecutive yearly blanket vaccinations with combined rinderpest and CBPP since $1992 / 93$, which had certainly contained the disease to a relatively low level during the past years by reducing the susceptible bovine population (Windsor et al, 1998).

The control of CBPP can be achieved by restriction of animal movement and stamping out of infected and exposed animals along with attendant zoo-sanitary measures. This requires adequate financial, infrastructural, and human resources and adequate information system. However, under the current Ethiopian situation, these control strategies could not be implemented to control and eradicate the disease. Therefore, control measures through vaccination and restriction animal movement remain the most practical option in the country. Therefore, to carry out an effective control of CBPP through strategic vaccination the prerequisites are a thorough understanding of the epidemiology of the disease in the country. In addition the current status of CBPP in the study area (Amaro special Wereda) is not known.

Therefore, the objectives of the study are to estimate the sero-prevalence of CBPP in the Amaro District of SNNP region and to identify the associated risk factors with the sero-prevalence of CBPP in the study area.

\section{MATERIALS AND METHOD}

\section{Study Area}

The study was conducted in SNNPR particularly in Amaro special District from November2014 to April 2015. Amaro is one of woreda in the Southern Nations, Nationalities, and Peoples Region (SNNPR) of Ethiopia. Because Amaro is not part of any Zone in the SNNPR, it is considered a special district, an administrative subdivision which is similar to an autonomous area. Located in the Great Rift Valley, Amaro is bordered on the south by Burji special woreda, on the southwest by Konso special woreda, on the west by Dirashe special woreda, on the north west by Gamo Gofa and Lake Chamo, and on the north and east by the Oromia Region. It is divided into 34 kebeles. The administrative center of the woreda is Kele (ADAO, 2013).

Amaro District is characterized by a mixed croplivestock farming system, in which herds are sedentary and large. Cattle are mostly of the Borena breed. Animals are used for agricultural activities, milk, meat production and manure. Based on the 2007 Census conducted by the Central Statistical Agency of Ethiopia (CSA), this district has a total population of 147,736 cattle, 49,127 Sheep, 74,777 goat, 3,746 equine 105,684 poultry and 17,858 bee hives. With an area of $1,422.16$ square kilometers, Amaro has a population density of 104.93; 8,633 or $5.78 \%$ are urban inhabitants. A total of 28,969 households were counted in this District, which results in an average of 5.15 persons to a household, and 27,941 housing units (ADAO, 2013). 


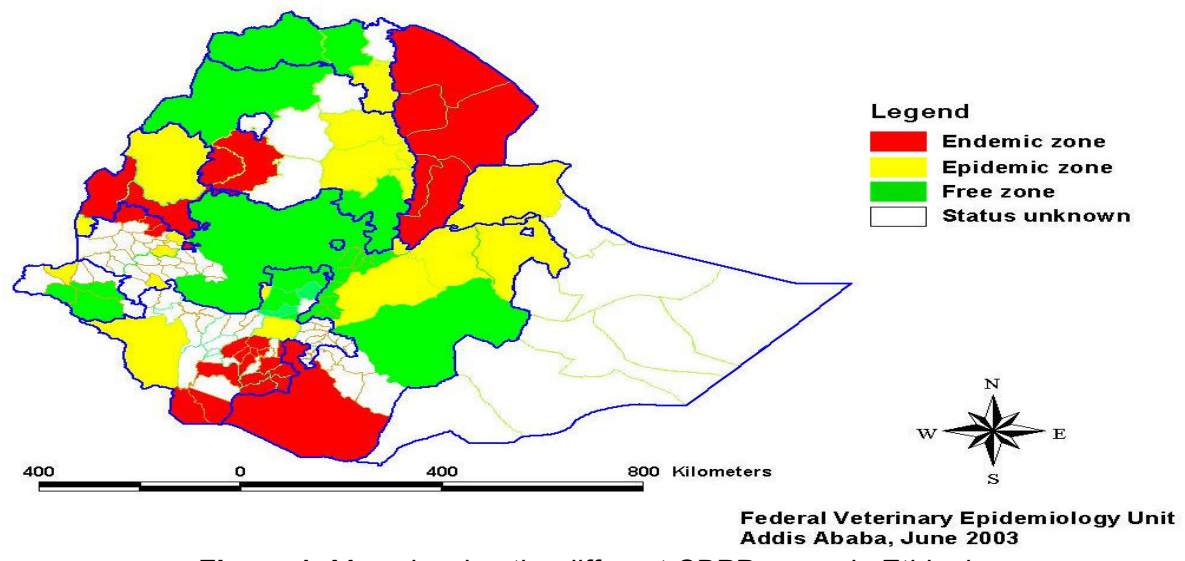

Figure 1: Map showing the different CBPP zones in Ethiopia

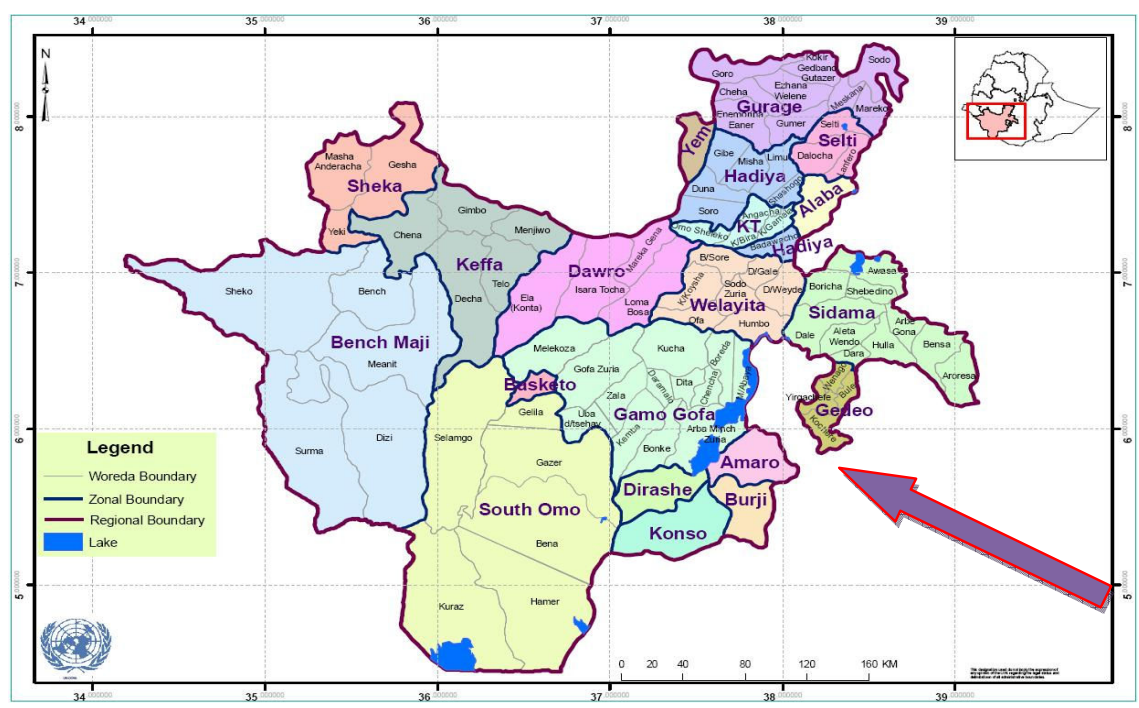

Figure 2: Map showing the study area

\section{Study Population}

The target study was conducted on bovine species including both sexes and age group above six months of age group in the study area.

\section{Study Design}

Across-sectional study design was conducted from November 2014 to April 2015 in Amaro special District; to estimate the sero-prevalence of CBPP in the Amaro District of SNNP region and to identify the associated risk factors with the sero-prevalence of CBPP in the study area.

\section{Sampling Methods}

The area was purposively selected based on certain criteria i.e. cattle population, accessibility and in addition the status of CBPP is not known yet in the area. A purposive sampling method was followed and first PA's were selected from the list then herds were selected and finally animals within the herds were identified. From the selected animals sera samples were collected along with other data/information to see the associated risk factors. Four peasant associations were purposively selected from the peasant association list and from each peasant association herds (households) were also selected randomly. During this study a total of 53 herds were surveyed from purposively selected four peasant associations in the study area (Amaro special District). Individual animals were randomly selected and from each herd $20 \%$ of animals judgmentally selected and serologically, examined.

\section{Sample Size Determination}

The number of animals sampled in the study area was estimated by using the formula described by Thrusfield (2005) with 95\% confidence interval.

$\mathrm{N}=\frac{1.96 \mathrm{x}^{2} \mathrm{P}(1-\mathrm{P})}{\mathrm{D} 2}=384$ samples for serological examination

Where $\mathrm{N}$ is number of animals sampled, $\mathrm{P}$ is the expected prevalence of the disease and $D$ is precision level (0.05). Expected prevalence of the disease was taken as $50 \%$ since no CBPP study conducted in the study area and to get the maximum sample size (384). To increase the precision sample size was inflated to 400 . From each herd $20 \%$ of animals were selected using the random sampling procedure (Thrusfield 2005).

\section{Blood Collection and Serum Extraction}

About $9 \mathrm{ml}$ of blood was drawn from the jugular vein using sterile 21 gauge needles and plain vacutainer tubes, which was labeled with herd and animal identification numbers. The blood was left slightly inclined at room 
Tolesa Ebisa et al.,

temperature for 24 hours and serum was collected into cryovials. Sera sample was stored at $-20^{\circ} \mathrm{C}$, till tested. The serum samples were analysed using competitive Enzyme Linked Immunosorbent Assay (c- ELISA) test which is based on a monoclonal anti-MmmSC antibody (Mab 117/5) test. This test was used to know the status of animals sampled in the study area based on NAHDIC test procedure and kit manufacturer instructions. The kit is based on a monoclonal anti-MmmSC antibody (Mab $117 / 5)$ test and test was conducted based on the procedures and methods of NAHDIC and by manufacturers of the kit instructions

\section{Competitive Enzyme Linked Immunosorbent Assay}

Microplates are coated with an MmmSC purified lysate. Samples to be tested are premixed with a specific monoclonal Antibody Mab 117/5 in a separate plate (preplate) and content of the "preplate" is transferred into the coated microplate. Any MmmSc specific antibodies present in the sample will form an immune -complex with MmmSc antigen coated micro plate, competing with Mab $117 / 5$ for the specific epitopes. After washing away unbound material, an anti- mouse Antibody enzyme Conjugate is added. In presence of immune-complex between MmmSC antigen and Antibodies from the sample, Mab 117/5 can bind to its specific epitopes and the conjugate is free to bind to Mab 117/5. Unbound conjugate is washed away and enzyme substrate is oxidized (TMB) is added. In presence of enzyme, the Substrate is oxidized and develops a blue compound becoming yellow after blocking. Subsequent color development is inversely proportional to the amount of anti-MmmSc Antibodies in the test sample.

\section{Data Analysis}

The collected data were stored in Microsoft office excel 2007 spreadsheet. Statistical analyses were
Sci. Technol. Arts Res. J., Oct-Dec 2015, 4(4): 106-112

performed using SPSS version 2.0 software. The overall sero-prevalence of CBPP was performed using descriptive statistics and calculated by dividing the number of positive test results by the total number of animals tested. Chi-square test was used to determine association between explanatory variables and the serostatus of the animals. In all analyses confidence level of $95 \%$ and $p-$ value of 0.05 was used for statistical test of significance.

\section{RESULT}

Prevalence of Contagious bovine Pleuropneumonia (CBPP) using c-ELISA

In the present study the sera were collected from 400 animals among 4 peasant association and examined by using Competitive Enzyme Linked Immunosorbent Assay(c-ELISA).The result of this examination reveals that 127 animals were appeared positive for the disease among sampled animals. The overall sero - prevalence of contagious bovine pleura pneuomonia in the study area was $31.8 \%(127 / 400)$. From 100 animals sampled from each peasant association the test indicated that $7,28,34$ and $58 \%$ animals were positive for the disease in Jello, kelle, Golbe and Gamule respectively. The highest CBPP seroprevalence (58\%) was observed in Gamule peasant association while the lowest seroprevalence $(7 \%)$ was recorded in Jello peasant association of Amaro special district of SNNPR. There was statistically significant variation $(p<0.05, \chi 2=60.95)$ in CBPP seroprevalence among the four peasant association. The result also indicated that the environment is the primary predisposing factor followed by body condition and herd size. The herd size sero-prevalence based on district is also significant with $32.3 \%$ in large herd size than in small herd size 19.8 $\%(p=14.972, x 2=.001)($ Table 1$)$

Table 1: Peasant association level sero-prevalence of Contagious Bovine Pleuropneumonia in Amaro special woreda SNNPR, Ethiopia in relation to predisposing factors

\begin{tabular}{|c|c|c|c|c|c|c|}
\hline Variables & Category & $\begin{array}{c}\text { Number of } \\
\text { tested animals }\end{array}$ & $\begin{array}{c}\text { Number of } \\
\text { positive animals }\end{array}$ & $\begin{array}{c}\text { Prevalence } \\
(\%)\end{array}$ & Chi-square & $P$-value \\
\hline & Jelo & 100 & 7 & $7 \%$ & \multirow{4}{*}{60.950} & \multirow{4}{*}{0.000} \\
\hline Peasant & kele & 100 & 28 & $28 \%$ & & \\
\hline \multirow[t]{2}{*}{ Association } & Golbe & 100 & 34 & $34 \%$ & & \\
\hline & Gamule & 100 & 58 & $58 \%$ & & \\
\hline \multirow{3}{*}{ Herd Size } & Small & 86 & 17 & $19.8 \%$ & \multirow{3}{*}{14.972} & \multirow{3}{*}{0.001} \\
\hline & Medium & 141 & 38 & $27 \%$ & & \\
\hline & Large & 226 & 73 & $32.3 \%$ & & \\
\hline \multirow{3}{*}{$\begin{array}{c}\text { Body } \\
\text { condition }\end{array}$} & Poor & 137 & 55 & $40 \%$ & \multirow{3}{*}{10.645} & \multirow{3}{*}{0.005} \\
\hline & Medium & 156 & 50 & $32.1 \%$ & & \\
\hline & Good & 107 & 22 & $20.6 \%$ & & \\
\hline
\end{tabular}

Host related potential risk factors like sex and age of the animals were assessed with CBPP serostatus of the animals however, none of these factors significantly explain $(P>0.05)$ the occurrence of CBPP.This indicated that host related variables were not potentially risk factors for the prevalence of the disease in Amaro district.

Table 2: Seroprevalence of CBPP analyzed against various host demographics

\begin{tabular}{ccccccc}
\hline Variables & Category & Number of tested & Number of positive & \% positive sample & 象 & P-value \\
\hline \multirow{2}{*}{ Sex } & Male & 174 & 73 & $31 \%$ & \multirow{2}{*}{0.073} & 0.787 \\
\cline { 2 - 6 } & Female & 226 & 73 & $32.3 \%$ & & \\
\hline \multirow{2}{*}{ Age } & Young & 213 & 62 & $29.1 \%$ & \multirow{2}{*}{0.625} & 0.429 \\
\cline { 2 - 6 } & Adult & 187 & 65 & $34.7 \%$ & & \\
\hline
\end{tabular}


Tolesa Ebisa et al.,

\section{DISCUSSION}

Based on this study using serological diagnoses, CBPP was found to be the major cattle health problem in Amaro District of the SNNP region. In this investigation a total of 400 serum samples were tested from 53 herds and four peasant associations of Amaro special District. Out of the 400 sera tested 127 (31.8\%) were found seropositive by c-ELISA. Sero-prevalence based on peasant association shows that it is highly significant in Gamule than in Jello at $58 \%$ and $7 \%$, respecively. The overall seroprevalence of CBPP in the study area was $31.8 \%$ (60.950, $P=0.000)$. This finding result is in agreement with the finding result report of western Ethiopia (Desta, 1997) which was $48 \%$ prevalence. However, it has agreement with the finding report of Yigezu and Roger (1997) and Gashaw (1998) reported prevalence range of $17 \%$ to $45 \%$. The herd size sero-prevalence based on district is also significant with $32.3 \%$ in large herd size than in small size $19.8 \%(P=14.972, x 2=.001)$. The higher sero-prevalence result obtained from this study might be attributed to the extensive cattle production system of the pastoralists and the epidemiology of the disease. The finding in the present study was similar to the work of Ragassa (2001) who reported seroprevalence of $28 \%$ in Bodji district of Western Wollega and the overall seroprevalence of CBPP in the present study was lower than the findings of Gedlu (2004) who reported seroprevalence of $39 \%$ in Somali regional state, and Dejene (1996) reported $56 \%$ seropositivity in North Omo. However, the overall seroprevalence of CBPP in the study area was higher than that of Ahmed (2004), Schnier et al. (2006), Gashaw (1998), Matua-Alumira et al. (2006), Kassaye and Molla (2013) who reported seroprevalence of $9.4 \%$ in Borena, $9.7 \%$ in south western Kenya, $9.1 \%$ in Northwest Ethiopia, $16 \%$ in Kajiado District Kenya, $4 \%$ in and around Adama respectively. The variation in the prevalence of CBPP reported from different parts of Ethiopia and other country could be due to difference in agro-ecology, management, production system, population density and the types of tests used to evaluate the seroprevalence.

The difference in the sero-prevalence result was significant in Gamule peasant association $58 \%$ than in Golbe (34\%), kelle (28\%) and Jelo (7\%). The higher prevalence reported in Gamule PA, could be due to large number of animals reared by an individual farmer and animals might have large grazing land so they have an access to contact with an infected animals from outbreak area. Similar higher herd seroprevalence results were recorded in study in Somale region (Gedlu, 2004) in Mie so district $(100 \%)$ followed by Qabribeyah (75\%), and Afdem $(71.4 \%)$. Also in Western Gojam and Awi zone the higher sero-prevalence results were also observed in Banja district $(66.3 \%)$ followed by Dangila $(41.7 \%)$ and Denbecha (33.3\%), (Gashaw, 1998).

In the present study, prevalence of disease based on their sex was $(31 \%)$ male and $(32.3 \%)$ female. The occurrence of the disease across sex factors showed that there was no significant statistical difference $(P>0.05)$ between male and female. This result was contradicted with Schnier (2006) who reported Female gender was significant.

The seroprevalence results of $31.92 \%$ and $31.55 \%$ were recorded in young and adult age categories, respectively which was not statistically significance. In age
Sci. Technol. Arts Res. J., Oct-Dec 2015, 4(4): 106-112

categories the seroprevlence was no statistical significant difference $(P>0.05)$ between young and adult. This result close agreement with previous report by (Emanuel, 2013) and Matua-Alumira et al. (2006) in which seropositive in adults would be higher as compared to the young. So that low prevalence of infection was due to the decreased contact between the other animal because young animal don't move long distance. But this result contradicted with report of Masiga et al. (1995) who reported young animals are susceptible to aricular forms of CBPP than adult cattle.

The present study used only c-ELISA test to categorize the cattle as CBPP seropositive and negative. It is well understood that C-ELISA is more sensitive in detecting cattle with chronic stage than any other test, and it is more prone to miss individual animals at the early stage of infection (Muuka et al., 2011; Schubert et al., 2011).

\section{CONCLUSIONS}

The result of the present study shows that CBPP is the prevalent disease in the Amaro district of SNNP region. In this study the herd sero-prevalence result in different peasant associations showed that it is highly significant $58 \%$ in Gamule and the lowest in Jello PA's $7 \%$. The overall individual animal level seroprevalence result was also higher (i.e. $31.8 \%$ ). This study revealed that CBPP is posing a major threat to cattle in Southern part of the country (Amaro Special Wereda). As the study indicated that the disease incidence was aggravated by predisposing factors like husbandry, environmental effects and herd size. Therefore, based on the results of this study the following recommendations are suggested;

- As a short term intervention and vaccination should be started to CBPP infected areas.

- In the long term annual vaccination should be given regularly in endemic area.

- Control of cattle movement

- Improve animal husbandry and managemental practices.

- Creating awareness about the disease to the communities should be implemented.

- Improvement of the public and private veterinary service delivery has a major impact in mitigating the risk imposed by CBPP.

\section{Conflict of Interest}

Conflict of Interest none declared.

\section{REFERENCES}

Abdo, E., Nicolet, J. and Frey, J. (2000). Antigenic and Genetic Characterization of Lipoprotein LppQ from Mycoplasma mycoides subsp. mycoides SC. Clinical and Diagnostic Laboratory Immunology 7(4): 588-595.

Ahmed, I. (2004). Epidemiological study of contagious bovine pleuropneumonia in Borana pastoral areas using Complement Fixation Test and Competitive EnzymeLinked Immunosorbent Assay, (Unpublished MSc thesis, Addis Ababa University)

Amanfu, W. (2000a). Contagious Bovine Pleuropneumonia Surveillance: The experience of Botswana. In: Report of second meeting of the FAO/OIE/OAU/IAEA consultative 
Tolesa Ebisa et alo, group on Contagious Bovine Pleuropneumonia (CBPP). Rome, Italy.

Amanfu, W., Sediadie, S., Masupu, K., Benkirane, A., Geiger, R. and Thiacourt, F. (1998). Field validation of a competitive enzyme-linked immunosorbent assay (cELISA) for the detection of Contagious Bovine Pleuropneumonia in Botswana. Revue D'élevage et De médecine Vétérinaire Des Pays Tropicaux 51(3): 189193.

Amanfu, W., Sediadie, S., Masupu, K., Raborokgwe, M., Benkirane, A., Geiger, R. and Thiaucourt, F. (2000b): Comparison between c-ELISA and CFT in Detecting Antibodies to Mycoplasma mycoides mycoides Biotype $\mathrm{SC}$ in Cattle Affected by CBPP in Botswana. Annals of the New York Academy of Sciences 916: 365-369.

Amaro District Agricultural Office (ADAO) (2007). Annual report on population size and agriculture of the district.

Asmamaw, (2003). Situation of CBCC in selected district of southern Ethiopia. MSC thesis, Faculty of veterinary medicine, Addis Ababa University, Debrezeit Ethiopia. Pp.371.

Bamhare, C. (2000). CBPP Surveillance in Vaccinated Areas: Namibia Experience with CBPP Vaccines Prepared from the T1-44 and T1-SR Strains. In: Report of second meeting of the FAO/OIE/OAU/IAEA consultative group on Contagious Bovine Pleuropneumonia (CBPP). Rome, Italy. Pp 79-87.

Bessin, R. and Connor, R. (2000). The PACE strategy for supporting the control of Contagious Bovine Pleuropneumonia (CBPP). In: Report of second meeting of the FAO/OIE/OAU/IAEA consultative group on Contagious Bovine Pleuropneumonia (CBPP). Rome, Italy. $\mathrm{Pp}$ 39-45.

Central Statistical Authority (CSA) (1998). Agricultural Sample Survey 1997/98, volume II. Statistical bulletin Number 193, Addis Ababa, Ethiopia.

Dejene, W. (1996). Contagious Bovine Pleuropneumonia (CBPP): Prevalence and Evaluation of Post-Vaccination immune response (North Omo, Konso and Dirashe Regions/Ethiopia). Addis Ababa University, Faculty of Veterinary Medicine, Debrezeit, Ethiopia, DVM thesis.Pp:37-48.

Desta, B. (1998): Sero-epidemiological Investigation of CBPP in llu Ababor and wellega (western Ethiopia), DVM thesis, AAU, FVM. Pp: 48.

Emanuel, S., Isidory, M., Edward, U., Adam, M. and Winford, M. (2013). An abattoir survey of contagious bovine pleuropneumonia lesions in slaughtered cattle in selected districts in Northern Tanzania. Asian Pacific Journal of Tropical Biomedicine 3(4): 303-306.

European Commission Health and Consumer Protection Directorate General. (2001). Report of the Scientific Committee on Animal Health and Welfare, SANCO/AH/R25/2001.

FAO (2002). Electronic Conference on Contagious Bovine Pleuropneumonia (CBPP) Comments and Discussions.

FAO EMPRES Unit. (1997). RECOGNISING CBPP, A Field Manual for Recognition.EMPRES FAO Animal Health Service Animal Production and Health Division Rome, Italy.

FAO EMPRES Unit. (2003). Control of Contagious Bovine Pleuropneumonia in Zambia.FAO/OIE/OAU/IAEA (2000): Consultative group on CONTAGIOUS BOVINE PLEUROPNEUMONIA (CBPP). Report of second
Sci. Technol. Arts Res. J., Oct-Dec 2015, 4(4): 106-112

meeting. Reviving progressive control of CBPP in Africa, Rome, Italy.

Fikru R., (2001).Herd prevalence of CBPP, Bovine tuberculosis and Dictyocaulosis in Budju woreda, West Wellega, DVM Thesis. Addis Ababa University, FVM Debre Zeit, Ethiopia. Pp, 328-329.

Gashaw, T. (1998). Epidemiological survey of CBPP in Awi and Western Gojjam zone of Amhara Region and comparison of CFT and C-ELISA for the diagnosis of CBPP, (Unpublished MSc thesis, Addis Ababa University and Freie Universität) Debrezeit, Ethiopia. Pp, 5.

Gedlu, M.G (2004). Serological, Clinical and Participatory epidemiological survey of CBPP in Somali Region. Unpublished MSc thesis, Addis AbabaUniversity, Addis Ababa University, Debrezeit Ethiopia. Pp: 75.

Kassaye , D. and and Molla ,W. (2013). Seroprevalence of contagious bovine pleuropneumonia at export quarantine centers in and around Adama, Ethiopia. Tropical Animal Health and Production 45: 275-279.

Litamoi, J. (2000). Overview of CBPP vaccine production and quality in Africa. In: Report of second meeting of the FAO/OIE/OAU/IAEA consultative group on Contagious Bovine Pleuropneumonia (CBPP). Rome, Italy.

March, J., Kerr, K., Lema, B. (2003): Rapid Detection of Contagious Bovine Pleuropneumonia by a Mycoplasma mycoides subsp. mycoides SC Capsular PolysaccharideSpecific Antigen Detection Latex Agglutination Test. Clinical and Diagnostic Laboratory Immunology 10(2): 233-240.

Masiga, W., Domenech, J., Windsor, R. (1996). Manifestation \& epidemiology of Contagious Bovine Pleuropneumonia in Africa. Revue Scientifique et Technique (International Office of Epizootics) 15 (4), 1241-1262.

Matua-Alumira, R., Ng'ang'a, Z., Kiara, H., Matere, C., Mbithi, F., Mwirigi, M., Marobella-Raborogwe, C. and Sidiadie, S. (2006). The prevalence of Contagious Bovine Pleuropneumonia (CBPP) in cattle under different production systems in Kajiado district, Kenya. Proceedings of the 11th Symposium on Veterinary Epidemiology and Economics 6-8th June 2006 Cairns, Canada.

MOA (1997). Livestock Development project. Ministry of Agriculture, the Federal Democratic Republic of Ethiopia. Addis Ababa, Ethiopia.

Monnerat, M., Thiaucourt, F., Poveda, J., Nicolet, J. and Frey, J. (1999). Genetic and Serological Analysis of Lipoprotein LppA in Mycoplasma mycoides subsp. Mycoides LC and Mycoplasma mycoides subsp. Capri. Clinical and Diagnostic Laboratory Immunology 6(2): 224230.

Msami, H., Ponela-Mlelwa, T., Mtei, B. and Kapaga, A (2001): Contagious Bovine Pleuropneumonia in Tanzania: Current status. Tropical Animal Health and Production 33 (1): 21-28

Muuka, G., Hang'ombe, B., Nalubamba, K., Kabilika, S., Mwambazi, L. and Muma, J. (2011). Comparison of Complement Fixation Test, Competitive ELISA and LppQ ELISA with Post-mortem Findings in the Diagnosis of Contagious Bovine Pleuropneumonia (CBPP). Tropical Animal Health and Production 43: 1057-1062.

NAHRC (2000). Report on CBPP Study in Ethiopia. Serosurveillance results National Animal Health Research Centre Ethiopian Agricultural Research Organization (EARO) Sebeta, Ethiopia. 


\section{Tolesa Ebisa et alo,}

Office International Des Epizooties (OIE) (2002). Manual of Standards for Diagnostic Tests and Vaccines.

Radostits, O., Blood, D. and Gay, C. (1994): Veterinary Medicine: A textbook of the diseases of cattle, sheep, pigs, goats and horses. $8^{\text {th }}$ ed. Baillière Tindall. Pp 910913.

Regassa, F. (2001). Herd prevalence of Contagious Bovine Pleuropneumonia (CBPP), Bovine Tuberculosis and Dictyocaulosis in Bodji woreda, west wellega. Addis Ababa University, Faculty of Veterinary Medicine, Debre zeit, Ethiopia, DVM thesis.

Rosendal, S. (1993). Mycoplasma. In: Gyles, C. L, and Charles, O. T. Pathogenesis of bacterial infections in animals. 2nd ed. Ames, IA: lowa State University. Pp 297311

Rurangirwa, F., Shompole, S., Wambugu, N. and McGuire, C. (2000). Monoclonal Antibody Differentiation of Mycoplasma mycoides subsp. mycoides Small-Colony Strains Causing Contagious Bovine Pleuropneumonia from Less Important Large-Colony Strains. Clinical and Diagnostic Laboratory Immunology 7(3): 519-521.

Scacchia, S., Tjipura-Zaire, G., Lelli, R., Sacchini, F. and Pini, A. (2011). Contagious bovine pleuropneumonia: humoral and pathological events in cattle infected by intubation and by exposure to infected animals. Veterinaria Italiana 47(4): 407-413.

Schnee, C., Heller, M., Jores, J., Tomaso, H. and Neubauer, $\mathrm{H}$. (2011). Assessment of a novel multiplex real-time PCR assay for the detection of the CBPP agent Mycoplasma mycoides subsp. mycoides SC through experimental infection in cattle. BMC Veterinary Research 7: 47.

Schnier ,C., Mtui-Malamsha, N., Cleaveland, S., Kiara, H., Grace, D., McKeever, D. and Zadoks, R. (2006): CBPP Seroprevalence and Associated Risk Factors In The Maasai Ecosystem Of South-western Kenya. Moredun Research Institute, Penicuik, UK.

Schubert, E., Sachse, K., Jores, J. and Heller, M., (2011). Serological testing of cattle experimentally infected with
Sci. Technol. Arts Res. J., Oct-Dec 2015, 4(4): 106-112

Mycoplasmamycoides subsp. mycoides small colony using four different tests reveals a variety of seroconversion patterns. BMC veterinary Research 7: 72.

Seifert, H.S.H. (1996). Tropical animal health. $2^{\text {nd }}$ Ed. The Netherlands: Kluwer Academic Publishers. Pp 332-339.

Tambi, E. N., Maina, O. W. (2004): Regional impact of CBPP in Africa. In: Regional Workshop on Validation of Strategies to Control CBPP in Participative PACE countries. Conakry, Guinea.

Tardy, F., Gaurivaud, P., Manso-Silván, L., Thiaucourt, F., Pellet, M. and Mercier P. (2011). Extended surveillance for CBPP in a free country: Challenges and solutions regarding the potential caprine reservoir. Preventive Veterinary Medicine 101(1-2): 89-95.

The World Bank (2001). Pastoral Area Development in Ethiopia: Issues Paper and Project Proposal, $1818 \mathrm{H}$ Street, N.W. Washington, D.C. 20433, U.S.A.

Thrusfield, M. (2005). Veterinary Epidemiology. 2nd ed. UK BlackWell Science. Pp.180.

Vilei, E.M., Abdo, E.M., Nicolet, J., Botelho, A., Gonçalves, R., Frey, J. (2000). Genomic and antigenic differences between the European and African/Australian clusters of Mycoplasma mycoides subsp. mycoides SC. Microbiology 146: $477-486$

Walker, L. R. (1999). Mollicutes: In Hirsh, D. C. and Zee, Y. C. Veterinary Microbiology. Blackwell Science, Inc. Pp 165-172.

Windsor, R.S. (2000). Changing Patterns of Contagious Bovine Pleuropneumonia in Southern and Eastern Africa. In: Report of second meeting of the FAO/OIE/OAU/IAEA consultative group on Contagious Bovine Pleuropneumonia (CBPP). Rome, Italy.

Windsor, R.S., Wood, A. (1998). Contagious Bovine Pleuropneumonia: The Costs of Control in Central/Southern Africa. Annals of the New York Academy of Sciences 849: 299-306. 